\title{
A Review of Low Altitude Manned Aviation Operations
}

\author{
Andrew Weinert, Gabriela Barrera \\ MIT Lincoln Laboratory \\ Email: \{andrew.weinert, gabriela.barrera\}@11.mit.edu
}

\begin{abstract}
With the integration of small unmanned aircraft systems into the U.S. National Airspace System, low altitude regions are being stressed in historically new ways. The FAA must understand and quantify the risk of collision between unmanned and manned aircraft during desired low altitude unmanned operations in order to produce regulations and standards. It is increasingly important to characterize how manned aircraft operate at these low altitudes, as historical assumptions are insufficient for modeling and simulation to support standards development. Yet technical challenges such as poor low altitude radar coverage and lack of required transponder equipage are significant barriers to characterizing the low altitude environment. In response, we conducted an extensive review of fixedwing and rotary-helicopter manned operations to characterize the low altitude environment.

keywords: aircraft; review
\end{abstract}

\section{INTRODUCTION}

Historically the majority of aviation operations occurred at altitudes above 1,200 ft AGL. Past air traffic management (ATM) technologies and models reflected this focus on operations above 1,200 ft AGL. Below 1,200 ft AGL there are niche operations by rotorcraft, special operations such as crop dusting, or fixed-wing manned aircraft transiting to or from higher altitudes. However, low altitude airspace is fundamentally evolving with the integration of small unmanned aircraft system (sUAS). Many current and envisioned sUAS operations primarily operate at lower altitudes [1]-[4].

DISTRIBUTION STATEMENT A. Approved for public release. Distribution is unlimited. This material is based upon work supported by the Federal Aviation Administration under Air Force Contract No. FA8702-15D-0001. Any opinions, findings, conclusions or recommendations expressed in this material are those of the author(s) and do not necessarily reflect the views of the Federal Aviation Administration. This document is derived from work done for the FAA (and possibly others), it is not the direct product of work done for the FAA. The information provided herein may include content supplied by third parties. Although the data and information contained herein has been produced or processed from sources believed to be reliable, the Federal Aviation Administration makes no warranty, expressed or implied, regarding the accuracy, adequacy, completeness, legality, reliability or usefulness of any information, conclusions or recommendations provided herein. Distribution of the information contained herein does not constitute an endorsement or warranty of the data or information provided herein by the Federal Aviation Administration or the U.S. Department of Transportation. Neither the Federal Aviation Administration nor the U.S. Department of Transportation shall be held liable for any improper or incorrect use of the information contained herein and assumes no responsibility for anyones use of the information. The Federal Aviation Administration and U.S. Department of Transportation shall not be liable for any claim for any loss, harm, or other damages arising from access to or use of data or information, including without limitation any direct, indirect, incidental, exemplary, special or consequential damages, even if advised of the possibility of such damages. The Federal Aviation Administration shall not be liable to anyone for any decision made or action taken, or not taken, in reliance on the information contained herein.

\section{A. Motivation}

To enable safe integration of sUASs, a current Federal Aviation Administration (FAA) interest is separation standards and risk analyses [5], [6]. Regulations and standards are required to mitigate collision risk to maintain a sufficient level of safety for sUASs which operate at low altitudes. They will enable, for example, sUAS-based package delivery in urban areas. It is increasingly important to characterize how manned aircraft operate at these low altitudes, as historical assumptions are insufficient for modeling and simulation to support standards development.

Some outdated assumptions include that in early Traffic Alert and Collision Avoidance System (TCAS) development, the program defined level flight as a vertical rate magnitude of less than $10 \mathrm{ft} / \mathrm{s}(600 \mathrm{ft} / \mathrm{min})$ [7], yet this is a reasonable sUAS rate for vertical transits. Early TCAS helicopter work considered aircraft from 0-300 ft AGL as "on-the-ground [8]." Current efforts to upgrade TCAS [9], [10] inherited many of the early assumptions scoped for higher altitudes operations at airspeeds of hundreds of knots [11].

These assumptions are partly a result of challenges such as poor radar coverage at low altitudes, lack of required transponder equipage, or minimal reporting requirements. Recent statistical models that characterize manned aircraft have an altitude floor of $500 \mathrm{ft}$ [12] and exclude the intended cruise altitude of many sUAS operations. Simple policy based assumptions are often inappropriate for low altitudes, such as always assuming a maximum airspeed of 250 knots defined by 14 Code of Federal Regulations (CFR) 91.117.

\section{B. Contribution and Objective}

In response we conducted an extensive literature review to classify commonly used low altitude aircraft and operations; quantify the differences between flight dynamics for specific operations vs. nominal cruise conditions for aircraft; determine how much operations have changed as technology evolved; and identify trends across different low altitude operations. Malicious operations, such as aircraft-assisted pilot suicides [13] or drug smuggling [14], are out of scope. Abnormal operations such as special event operations or radiological surveys [15] are also out of scope. This review is complimented by a previous effort to characterize and model sUAS operations [16]. 


\section{Specialized Non-SURVEILlance OPERATIONS}

General aviation operations and some commercial operations are codified in the 14 CFR 91, "General Operating and Flight Rules." Most commercial operations are controlled by 14 CFR Parts 119, 121, 125, 129, and 135. Helicopter operations often fall under Part 135; for example commuter operates carrying nine passengers or less; or on-demand operations, including helicopter air ambulances (HAAs). Part 121 operations are more stringent than Part 135 and encompass regional and major scheduled air carrier operations. Specialized operations such as commercial air tours and national parks air tour management and agricultural aircraft operations are codified in Parts 136 and 137.

\section{A. Agricultural Aircraft Operations - Material Release}

Spraying and dusting applications, along with related operations, are codified in the 14 CFR 137, "Agricultural Aircraft Operations." There are extremely limited reporting requirements for Part 137 operations and agricultural operations are often considered to be one of the hardest operations to surveil due lower operating altitudes and lack of widespread transponder equipage.

Cantor and Booze in 1991 [17] identified approximately 10,000 persons who indicated "aerial application" activity from 1965-1979. In 2009 the Iowa Department of Transportation Office of Aviation released a report on aviation's impact on the state's economy [18] noting that $86 \%$ of Iowa's general aviation airports support agricultural aircraft operations. Additionally, the Iowa Agriculture Aviation Association noted in 2006 [19] that most of their association members do not use radios nor did the FAA require radio use then; they also noted complaints by some airports regarding the lack of notification prior to agricultural operations. While these issues were noted over a decade ago, we believe that the limited policy changes since 2006 would likely have not addressed these issues; that the issues may still be prevalent.

We also reviewed a 28-year retrospective investigation of agricultural aviation accidents from 1982-2009 by van Doorn [20], specifically 3,102 fixed-wing aircraft crop dusting missions conducted under Part 137. They note that unscheduled flights and specific functions partly define manned aerial application operations. They identified that accidents were more frequent during the summer and that the accident's location, month, day, or time were not indicative factors when characterizing accidents. An increased frequency of accidents in the summer was previously identified by Reich and Bener in 1968 [21], which align with the warmer growing season months of May through September [22].

1) Dusting and Spraying: Starting in 1938, Watson et al. [23] described larvicidal control dusting operations with dispersion at altitudes of 6-10 ft AGL and 20-30 ft AGL. Watson noted that applying when below $30 \mathrm{ft}$ AGL enable accurate applications and the fixed-wing Piper PA-18A Super Cub was a popular for agriculture. Also in 1938, Kiker et al. [24] noted they limited routine flights to early morning hours due to meteorological conditions, while dusting at 7080 knots from about $25 \mathrm{ft}$ AGL. More importantly, Kiker et al. recorded they dusted 72 of the 140 days of the growing season while accumulating 195 flight hours with each dusting flight averaging 2.25 hours. While aviation has changed since the 1930's, Kiker's documentation helps bound the frequency and duration of agricultural aircraft operations. Sixteen years later in 1954, Weick [25] reported that dusting occurs at 5070 knots from 2-8 ft AGL.

Many experimental spraying efforts employed fixed-wing aircraft from Air Tractor [26]-[31]. As reported in TABLE I, while the Air Tractor aircraft changes from 1988 [26] to 2017 [28], the spraying altitudes of approximately 6-20 ft AGL and airspeeds of 97-120 knots were similar.

TABLE I

SPRAYING ALTITUDE AND AIRSPEEDS FOR AIR TRACTOR AIRCRAFT

\begin{tabular}{lll} 
Aircraft (Author) & Altitude (ft AGL) & Airspeed (knots) \\
\hline Air Tractor 301 (Forsyth) [26] & $6-10$ & $97-108$ \\
Air Tractor 402B (Kirk) [27] & $6-10$ & 120 \\
Air Tractor 402B (Huang) [28] & 12 & 120 \\
Air Tractor 402B (Huang) [29] & $12-20$ & - \\
Air Tractor 502B (Woods) [30] & 9 & 115 \\
Air Tractor 602 (Barbosa) [31] & 10 & 105 \\
\hline
\end{tabular}

2) Insect Release: Tan and Tan identified commonly used manned aircraft to release insects into the wild as part of a sterile insect technique for biological pest control [32]. They identified the following manned aircraft used for insect dispersion: Beechcraft King Air 90; Cessna 172, 206, 207, 208, 401, 402; Helicopter Bell 206, 212; Piper PA-28; and Let L-410 Turbolet. Without validating flight data and based on published guidance [33], they reported an operational altitude range of approximately 300-2,500 ft AGL and average airspeeds of 78-88 knots.

3) Fish Release: Cooper in 1957 described dispersing fish using a Cessna 180 from an altitude of 200-300 ft AGL at about 70 knots [34]. While aerial restocking of fish missions have been conducted since the 1950's, it appears little has changed. Hallows in 2007 described a Cessna 185 releasing fish from an altitude of $150 \mathrm{ft}$ AGL [35].

\section{B. Helicopter Air Ambulance}

A HAA operation involves moving a patient between healthcare facilities or to a facility from an accident, and operate under 14 CFR 135. Due to their life-saving missions, HAA often receive priority handling from air traffic control (ATC), with ATC likely to request other aircraft to separate away from the HAA [36]. HAA operations are also intended to be completed as quickly as possible with HAA pilots reporting few delays when operating in controlled airspace [37].

Across our review, many publications identified that data on HAA total operations, flight hours, etc. were not available or discoverable. This data gap of limited flight data is highlighted by a 2007 U.S. Government Accountability Office report [38], which attributes this lack of available due to a lack of reporting requirements for Part 135 operations. As a consequence of lack of data, most publications report general statistics, such as raw accident rate.

Statistics regarding the United States HAA industry include the FAA reporting in 2014 that 75 air ambulance companies 
operated approximately 1,515 helicopters [39]; the Association of Air Medical Services estimated there was 400,000 annual rotor wing transports [40]; and the Helicopter Association International estimated annual HAA flight hours grew from 162,000 hours in 1991 to over 300,000 hours in 2005 [41].

Specifically, Wright [42] cited annual HAA flight hours from 1991 to 2004 to support an analysis of the HAA accident rate in 2004. Fig. 1 replicates the total flight hours as cited by Wright. Notably, Wright cites a similar flight hour total for 1991 as the Helicopter Association International. It is unknown if Wright obtained the 1991 estimate directly the from Helicopter Association International or vice versa. Unfortunately, these estimates do not align with the FAA estimation that HAAs flew 900,000 hours annually from 19932003 and increased to $1,600,000$ hours in 2004 [38]. Due to the lack of reporting, the U.S. Government Accountability Office considers these estimates as "questionable [38]."

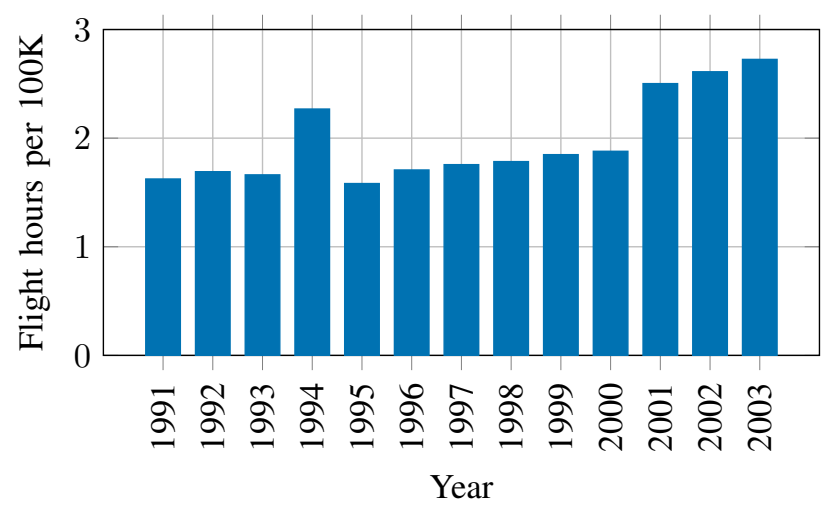

Fig. 1. Total HAA flight hours as reported by Wright [42].

While nationwide statistics are less than ideal, we identified better reporting at state and local levels. For example in 2008, the Maryland state police [43] employed 12 Eurocopter AS365 Dauphin helicopters, with some purchased and placed in service almost twenty years earlier. Annually from 20032007, they averaged 8,022 helicopter missions and 4,745 flight hours (standard deviation of 233 hours). The majority of these can be considered HAA, averaging 5,135 missions annually. Interestingly the command formally operated under Part 91 but voluntarily implemented many policies that mirror Part 135.

Another more detailed study was a survey by Newman [44] of 153 operators and their company's visual flight rules (VFR) weather minimums, which are the worst-case meteorological conditions that an aircraft can operate under VFR rules. Newman's results in Fig. 2 are categorized by duration and time of day. Companies imposed more restrictive VFR minimums during the day. For example, 105 operators reported a policy permitting daytime VFR operations if operating locally and the altitude ceiling was at least $500 \mathrm{ft}$. The higher minimums for cross country operations are reflective of higher cruise altitudes. Newman concluded that the majority of operations met VFR minimums, given the operating area and policy. This analysis indicates that HAAs were unlikely to operate under instrument flight rules (IFR) simply due to the weather. While Newman's study is decades old, we assume operators are still safety focused.

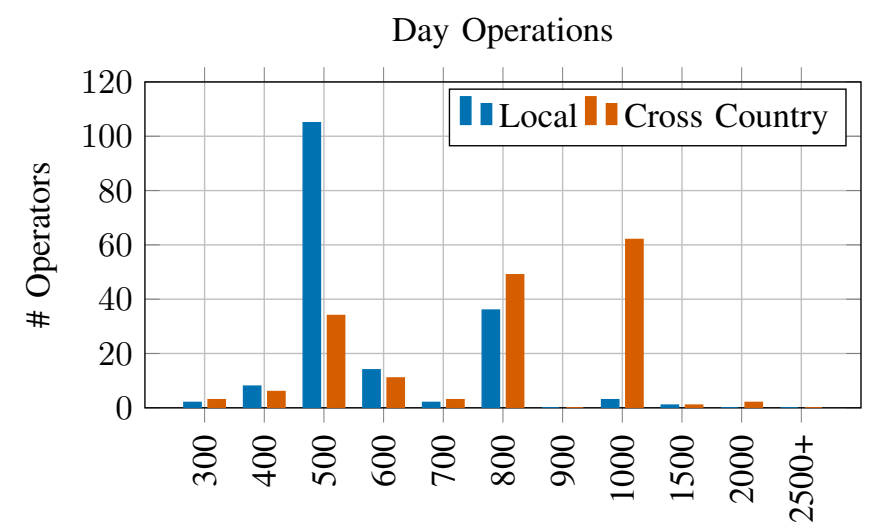

Night Operations

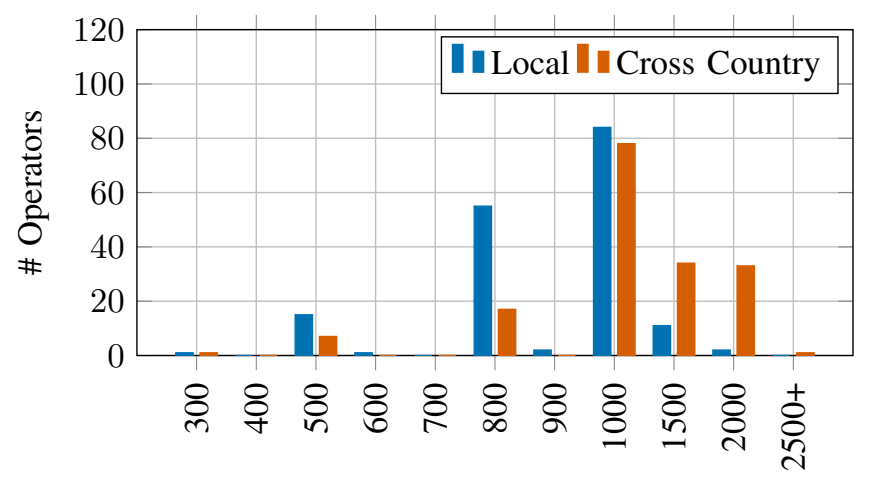

VFR Minimum Altitude Ceiling (ft AGL)

Fig. 2. Frequency distributions of VFR minimums company altitude ceilings by Newman [44]. Note that the $\mathrm{x}$-axis is not entirely linear.

\section{Helicopter Air Tours}

Helicopter sightseeing air tours are commercial operations regulated by 14 CFR 91.147, "Passenger carrying flights for compensation or hire." They often take-off and land at the same location and fly a short route around attractions.

Besides the CFR, local specific rules can exist for air tours. New York City, for example, restricts air tours to flying over water [45]; and as part of VFR corridor above the Hudson River [46], [47], there is an air tour loitering corridor from $0-1,000 \mathrm{ft}$ AGL and transit corridor without ATC coordination from 1,000-13,000 ft AGL. These corridors have a speed limit of 140 knots. Recently in 2016, New York City reached an agreement with air tour operators to reduce the quantity of air tours due to noise and pollution concerns [48]. Las Vegas also implemented similar polices in response to noise complaints [49]. Noise complaints in Kansas City led to an increase in cruise altitude from $500 \mathrm{ft}$ AGL to $700 \mathrm{ft}$ AGL [50]. Another example is Special Federal Aviation Regulation (SFAR) 71, which from 1994 to 2003, set a minimum air tour altitude of 1,500 ft AGL over Hawaii, resulting in a $41 \%$ decrease in crashes [51].

Similar to other specialized operations, nationwide total operations and flight hour data were difficult to obtain, and while still difficult to find, some local statistics are available. For one the busiest domestic air tour locations, a New 
York City industry report estimated there was approximately 42,000 sightseeing air tours over New York City in 2010 [52]; total air tours eventually increased to over 50,000 flights.

1) Sightseeing: The flight plans are generally predefined and operators do not have strict ATC coordination requirements. Instead of specific operating altitudes, the operating altitudes on a given day is weather dependent and the minimum altitude often differs when operating over land or water. TABLE II reports the targeted cruise AGL altitude for various operators and routes based on company websites and a few informal phone surveys. The average cruise altitude was approximately 1,200 ft AGL, with the majority of altitudes less than the average. Lower altitudes maybe flown to accommodate better sightseeing.

TABLE II

HELICOPTER SIGHTSEEING TARGET AGL ALTITUDES

\begin{tabular}{lll} 
Location & Operator (Route) & Altitude (ft) \\
\hline Chicago & Chicago Helicopter Tours [53] & $700-1000$ \\
Hawaii & Blue Hawaii (Circle of Fire) [54] & 500 \\
Hawaii & Sunshine Helicopters (Big Island) [55] & $1000-2000$ \\
Kansas City & Multiple [50] & $500-700$ \\
Lancaster & Smoketown Helicopters [56] & 1000 \\
Las Vegas & Las Vegas Night Strip [57] & 3300 \\
Las Vegas & Sundance (Twilight City) [58] & 1200 \\
Las Vegas & Sundance (Las Vegas Strip) [58] & 800 \\
Maui & Maverick (Molokai Voyage) [59] & 3000 \\
Newport & Bird's Eye View (Over water) [60] & $400-500$ \\
Newport & Bird's Eye View (Over land) [60] & 1000 \\
New York City & HeliNY.com [61] & $900-1500$ \\
New York City & Zip Aviation [62] & $1500-2000$ \\
Pittsburgh & Pittsburgh Helicopter Rides [63] & 2000 \\
\hline
\end{tabular}

Regarding specific aircraft, the Airbus Eurocopter EC130 / H130 are popular, and was developed in conjunction with and delivered first to air tour operations [64]. Operators in Kansas City, Chicago Helicopter Tours and Smoketown Helicopters fly the Robinson R44 [50], [53], [56].

2) National Parks: Helicopter air tours also include operations in national parks or transport for back country skiing. Surprisingly, one of the best references for flight hour statistics was found in a U.S. Department of Agriculture funded research on Golden Eagles. Grubb et al. [65] analyzed historical flight records from 1981-2007 for the Wasatch Powderbird Guides, who operate with a special heli-sking permit in the Tri-Canyon Area in Utah's Wasatch Mountain. They employed AStar AS350 helicopters, along with Bell 206L4 Longrangers. Over a 34 year period with an average annual 120 days skiing season, Wasatch Powderbird Guides operated 62.4 days annually with an average of 210.6 flight hours annually; Grubb et al. noted that total flight hours had limited variation over the years. Additionally, Goldstein et al. [66] reported 1,952 helicopter landings for skiing in Chugach National Forest, Alaska during the winter of 2004. Goldsein also experimented with AStar AS350 helicopters flying at approximately 99 knots.

\section{Helicopter Offshore Operations}

Offshore operations involve the transport of passengers or supplies between at least one site located offshore in the ocean, such as an oil platform. FAA AC 90-80B [67], recently canceled in December 2017, previously advised the appropriate procedures and methods to obtain approval for off-shore operation; a 5+ nm nearly straight approach was prescribed. Similarly, The European satellite based augmentation system (SBAS) offshore approach procedure [68] for operations in support of the oil and gas industry, prescribes a nearly straight approach, akin to the approach recommended by FAA AC 9080B. For SBAS offshore approach simulations, helicopter altitude was set to 2,000 ft with an initial airspeed of 80 knots and a constant heading.

Offshore operations are often compared to HAA operations. However, the Bye et al. [69] comparison of offshore and onshore transportation helicopter operations indicate significant differences between the two types. While similar aircraft maybe used, helicopter offshore transport operate differently than HAAs. Dunnet [70] observed low flying helicopters and Piper PA-23 Aztecs operating at about $500 \mathrm{ft}$ AGL near the coastline.

For fleet statistics, TABLE III reproduces the Helicopter Safety Advisory Conference reported summary statistics for Gulf of Mexico offshore operations for 491,697 flights and 188,799 flight hours in 2017 across ten operators [71]. The total fleet was 329 helicopters constituted primarily by of 182 single-engine aircraft flying 116,408 hours.

TABLE III

GULF OF MEXICO OFFSHORE HELICOPTER OPERATIONAL SUMMARY [71]

\begin{tabular}{lrrr} 
Metric & 2015 & 2016 & 2017 \\
\hline Hours Flown (fleet) & 228,905 & 196,484 & 188,799 \\
Annual Flights (fleet) & 589,078 & 526,981 & 491,697 \\
Flights Per Day (fleet) & 1,614 & 1,444 & 1,347 \\
Flights Per Aircraft & 1,703 & 1,532 & 1,495 \\
Annual Hours per Aircraft & 662 & 571 & 574 \\
Average Flight Duration (min) & 24 & 22 & 23 \\
\hline
\end{tabular}

\section{E. Training}

Flight schools and flight training are regulated under 14 CFR Parts 61 and 141, with at least 40 flight hours required to earn a private pilot's certificate. While these regulations are detailed in defining training, they do not recommended specific aircraft to complete the training. As trainees first fly under VFR, our review attempted to identify which aircraft are commonly used for training purposes.

Christensen and Dunn [72] analyzed 31 collegiate aviation flight programs while identifying 98 programs in 2011. They identified 43 primary training aircraft, with about half being either a Cessna 152 or 172; other aircraft were single engine from Cirrus, Diamond, and Piper. Forty of these aircraft accrued 200-799 flight hours annually. Additionally, various experimental training efforts have employed the single engine Diamond DA-40 aircraft [73]-[75].

\section{REMOTE SENSING OpERATIONS}

Besides air carrier and passenger operations, aircraft are often used for remote sensing operations. These often involve a sensor taking images or measurements from an aircraft to characterize the surface. Some sensors, such as the MODISASTER (MASTER) [76], have been deployed for different use 
cases. Whereas the previous Section II focused on operations enabled by specific regulations, such as crop dusting under 14 CFR 137, remote sensing has a much wider scope. We reviewed remote sensing operations based on sensor or use cases [77] of animal, earth, hydrospheric, plant sciences, and lastly news-gathering.

\section{A. Animal Sciences}

Remote sensing for animal sciences are generally either counting the quantity of a specific species or observing an animal's habitat. While generally low, the operating altitudes for animal sciences are dependent upon many factors, such as the species of wild life being observed. Across our review, we found the animal science community to have the most documentation rigor. For example, Stoll et al. explains their methodology of counting deer as:

"We obtained counts by systematically searching along 100-300 m wide transects at altitudes of 45$60 \mathrm{~m}$ and at airspeeds of 35-70 km/hr [78]."

We noted that many of these operations occur in regions with low human population density and subsequently low manned air traffic density. However, animal sciences [79]-[83] has emerged as a discipline where unmanned aircraft system (UAS) can have a transformative affect; the future of animal science may look very different.

Wildlife searches generally involve one pilot flying the aircraft and two spotters identifying and counting a specific animal species. TABLE IV contains the search altitude and airspeed for different animals in publications spanning from 1981 [84] to 2017 [85]. The majority of them flew a helicopter along a systematic route below $200 \mathrm{ft}$ AGL at 40 knots or less. Mission profiles like these were not accounted for in previous studies assessing the collision risk with UAS [5], [6].

TABLE IV

MISSION PROFILES OF WILDLIFE SEARCHES

\begin{tabular}{lll} 
Aircraft (Author) & $\begin{array}{l}\text { Altitude } \\
\text { (ft AGL) }\end{array}$ & $\begin{array}{l}\text { Airspeeds } \\
\text { (knots) }\end{array}$ \\
\hline Bell 47 (DeYoung) [86] & 75 & 30 \\
Bell 47-G3B-1 (Beasom) [87] & $30-50$ & $30-35$ \\
Bell 206L, Bell 206B (Potvin) [88] & 200 & $37-54$ \\
Bell 206L, Enstrom 408B (Jung) [89] & 558 & $49-65$ \\
Bell G4-A, Bell Jet Ranger III (Beasom) [84] & 65 & $14-16$ \\
Bell Jet Ranger (Beringer) [90] & 200 & 23 \\
Bell Soloy (Bartmann) [91] & $80-115$ & 33 \\
Cessna 206 (Jachmann) [92] & $350-450$ & $?$ \\
Hiller UH 12 E, Hiller UH 12 E-4 (Stoll) [78] & $145-200$ & $19-38$ \\
Piper Navajo 350 (Courtois) [93] & 656 & 108 \\
Piper Supercub, Scout (Christie) [85] & $250-348$ & 70 \\
Robinson R22 (Timmer) [94] & 49 & 33 \\
- (Daniels) [95] & $100-164$ & - \\
\hline
\end{tabular}

In addition to our review, Courtois [93] conducted a survey of 30 publications detailing 83 Caribou aerial searches with fixed-wing and rotary-wing aircraft. Courtois found that Caribou searches are generally conducted below $800 \mathrm{ft}$ at less than 100 knots. Another review by Chabot and Francis [96] focused on 19 papers on bird counting where the manned aircraft altitude ranged from about $300 \mathrm{ft}$ AGL [97] to 4,590 ft AGL [98] with an average across publications of about 1,940 ft AGL.
Overall, there is significant evidence that wildlife searches overwhelmingly operate at low altitudes.

Conversely, the mapping of animal habitats occurs at a wider range of higher altitudes. Chust et al. [99] mapped coastal habits using a Rockwell Aero Commander 690 at about 1,310 ft AGL flying at approximately 156 knots, and intertidal habits were mapped at 3,740 ft AGL by Garono et al. [100], using a spectrographic imager mounted on a De Havilland Canada DHC-2 Beaver flying at approximately 95 knots. Coastal measurements have also been collected from 650-2,600 ft AGL from a De Havilland DHC-6 Twin Otter flying at approximately 100 knots [101]. Similar targets can also be surveilled at widely different altitudes. For example, coral reef habitats were mapped using a De Havilland Dash 8-200 at 1,200-2,200 ft AGL flying at 140-175 knots as reported by Costa et al. [102], but Capolsini et al. [103] used the MASTER from approximately 26,000 ft AGL on a Douglas DC-8. Additionally, habitat mapping isn't solely conducted at low altitudes; Dalsted et al. [104] conducted ground measurements of general vegetation of prairie dog towns at 4,495 ft AGL onboard a Beechcraft D-18.

\section{B. Earth Sciences}

Earth science observations include sensing of the soil and landscape, hydrospheric sciences, and thermography. We found during our review that earth science missions are often not flown at low altitudes [105]-[111]. However, technology advancement can lead to operational changes. In 1995, Jackson et al. [112] mapped soil moisture using an L-band electronically scanned thinned array radiometer. Data collection was through NASA aircraft C-130 Hercules and DC-8 at a nominal altitude of $656 \mathrm{ft}$. These two aircraft are much larger than the other aircraft researched, the sensing technology from over two decades ago likely necessitated the larger aircraft. Furthermore slower airspeeds less than 100 knots are not unique to the low altitude either, Costa et al. [113] mapped intertidal vegetation from 5,000 ft at only 85 knots.

At lower altitudes, artic shrub biomass was observed from about 1,200 ft AGL by Greaves et al [114]; Caudle et al. [115] deployed at Cessna Stationaire 206 at about 2,130 ft AGL to measure beaches and dunes; and Massarelli et al. [116] detected asbestos containing materials using an airborne hyperspectral sensor aboard an unspecified twin-engine, fixedwing aircraft at $985 \mathrm{ft}$ MSL cruising approximately 120 knots. Marcot et al. [117] also used a Cessna 206, along with a Cessna 185, to map Alaskan land cover from an average altitude of $985 \mathrm{ft}$ AGL with an estimated average ground speed of 90 knots.

Torgersen et al. [118] measured stream patterns and thermal factors using a thermal infrared system. The system was mounted on a Bell 206B-3 helicopter with typical flight altitudes of 985-290 ft AGL and ground speeds were maintained at 27 knots over narrow streams to 49 knots over wide rivers. Honkavaara et al. [119] used a Cessna 172 Reims Rocket at 1,440 ft flying 75 knots to collect three-dimensional spectrometric data to assess water quality.

Thermography is another earth science application. Mahrt and Hearld [120] operated as low as $100 \mathrm{ft}$ AGL before sunrise 
for temperature sensing experiments; Kustas et al. operating at approximately $500 \mathrm{ft}$ AGL over a corn field [121] for infrared sensing; and Voogt and Grimmond [122] used low-altitude helicopter flights at 1,500-2,120 ft to extract temperatures for modeling surface heat flux.

\section{Plant Sciences}

Our review of plant sciences largely focused on agriculture and their comparison to forestry operations. These remote sensing operations tended to occur at higher altitudes than the material release operations reviewed in Section II-A.

A common manned aircraft use case is remote sensing and hyperspectral imaging for agricultural sensing and detection of vegetation types and plant diseases. Foremost, Pinter et al. [123] published a review in 2003 of remote sensing of water, nutrients, and pests in agricultural crops and assessed the role of remote sensing in yield prediction, however they did not analyze nor aggregate or analyze the operational envelope or performance of any aircraft conducting the remote sensing missions under review. Pinter et al. noted that thermalinfrared sensing via aircraft has not been widely available and is potentially underutilized by thermal irrigation scheduling algorithms. They referenced Moran [124] who conducted thermal-infrared sensing of the Maricopa Agricultural Center at approximately $330 \mathrm{ft}$ AGL.

It is also important to note that many remote sensing missions occur above the very low altitudes discussed here and are summarized in TABLE V. When time of flight was documented, the majority of the operations occurred in late morning through early afternoon. Also, both the Air Tractor 402B and Cessna 206 were identified for Part 137-like spraying operations.

TABLE V

MISSION PROFILES OF REMOTE SENSING FOR AGRICULTURE

\begin{tabular}{|c|c|c|}
\hline Aircraft (Author) & $\begin{array}{l}\text { Altitude } \\
\text { AGL) }\end{array}$ & Sensing target \\
\hline ? (Huang) [125] & 1200 & Plant growth \\
\hline Cessna (Finn) [126] & 6,000 & Soil moisture \\
\hline Cessna 206 (Yang) [127] & 4,600 & Plant growth \\
\hline Cessna 206 (Yang) [128] & 1,000 & Pest detection \\
\hline Cessna TU206 (Xia) [129] & $780-1600$ & Evapotranspiration \\
\hline Piper PA-18S (Macomber) [130] & & Vegetation \\
\hline Piper PA-31 (Krishnan) [131] & 880 & Temperature \\
\hline Piper PA-31 (Sampson) [132] & $3280-9840$ & $\begin{array}{l}\text { Forest } \\
\text { conditions }\end{array}$ \\
\hline
\end{tabular}

An important takeaway of TABLE $\mathrm{V}$ is that for a given aircraft the available sensor technology and targets of interest influence the operating altitudes. Technology advancement of assumed better sensor resolution or quality doesn't necessarily result in higher operating altitudes. Yang et al. employed a Cessna 206 for two different sensing targets. Yang et al. [127] published in the year 2000 sensed plant growth at 4,600 ft AGL. Over a decade latter, Yang et al. [128] in 2014 used a multispectral imaging system for various agricultural applications (including pest detection), and this system was installed in a Cessna 206. Airborne images were taken at altitudes of $1,000 \mathrm{ft}$ at approximately 108 knots.
In 1985, Menges et al. [133] used aerial photography, along with ground spectral measurements, to distinguish weeds from crops. Aerial photographs were collected from about 1,970$32,000 \mathrm{ft}$. More recently by Liebisch et al. [134], thermal imagery supported phenotyping crop breeding, in which a sensor array was operated on a Zeppeling aircraft at altitudes of 952-1,017 ft at up to a slow 11 knots.

In comparison, operations for forestry, the science of planting, managing, and caring for forests, tend to be at higher altitudes. Nsi et al. [135] used a Cessna 172 at 1,640 ft to assess the health of trees at risk of bark beetle infestation. Forest conditions were examined by Sampson et al. [132] using a compact airborne spectrographic imager, for which measurements were taken in July 1998 on a Piper PA-31 Navajo Chieftain at three altitudes: $3,280 \mathrm{ft}, 6,560 \mathrm{ft}$, and 9,840 ft. More recently, Caldern et al. [136] used a hyperspectral sensor and broad-band thermal camera on board a Cessna aircraft, with both cameras flown at about 1,640 ft AGL; and Niemann et al. [137] examined spectral properties of infected trees using a spectrometer with data acquired at 4,900 ft AGL.

The U.S. Forest Service also conducts low altitude operations. In 2015 Kliment et al. [138] analyzed 2,942 hours of data from 1,853 flights across seven Beechcraft King Air used for aerial surveillance by the U.S. Forest Service. This flight data also supported research into low altitude gust velocities by Rokhsaz and Kliment [139]. Kilment et al. [140] followed in 2018 with another analysis of 7,076 flight hours flown by the seven U.S. Forest Service aircraft. They summarized that of the 7,076 flight hours, 367 hours were flown at 0-500 ft. AGL and 1,790 hours at 500-1,500 ft. AGL; this constitutes about $30 \%$ of total flight time from the years 2009-2014. Across altitudes, the maximum indicated airspeed was never less than 125 knots and majority of maximum indicated airspeeds were at least 200 knots.

\section{Helicopter Electronic News-gathering and Public Safety}

News companies and public safety often employ helicopters to obtain imagery of routine vehicle traffic congestion, events, or disasters. Depending on the region, helicopters from multiple agencies could be operating near each other and reporting on the same incident. Remarkably, assuming this is a common use case, it was one of the most difficult to identify appropriate publications and information for our review.

1) News-gathering: Strikingly, the most fruitful analysis was based on publications focused on wildlife protection and pollutants. Grubb et al. [65] identified that KUTV Utah news channel employed a Bell 206 L4 in 2007 while Crosman et al. [141] instrumented the Utah KSL Bell 206L3 news helicopter from summer 2015-summer 2016. Crosman et al. observed that about $70 \%$ of flights occur between 1500 1800 hours MST and operate 3-6 times per week with the primary use to observe afternoon vehicle traffic. During flights, the Bell 206L3 had a median flight duration of 56 mins. It's cruise speed ranged 77-136 knots with a mean of 97 knots. When hovering or surveiling a fixed target, it flew up to approximately 20 knots. Crosman et al. also asserted the helicopter operated between 1,300-3,280 ft AGL. 
The operating altitudes aligns with a statement by the news director for a local Bay Area, California news channel in 2011 who asserted a preference to fly above 1,000 ft AGL, unless lower operating altitudes are required due to meteorological conditions, such as cloud cover [142]. It is also within the range of 330-6,560 ft AGL assumed by Gui et al. [143] for optimizing the communications of airborne imagery from news gathering helicopters.

2) Incident and Disaster Response: In Lega et al. [144], thermal tracking operations to assist police investigations using an on-board infrared camera was conducted using various aerial platforms, such as an AgustaWestland AW109N helicopter. Alpert [145] described in 1998 Schweizer 300-C and Miami-Dade Jet B206L-4 helicopters equipped with infrared heat sensors operating in Baltimore; he also noted that routine Baltimore police department helicopter patrols occurs at $500 \mathrm{ft}$ AGL. Lega et al. [144] described thermal tracking applications to assist police investigations using various aerial platforms, including A109N, A412 helicopters equipped with IR cameras. Recently in Germany, Amendt et al. [146] experimented with detecting cadavers with thermal imagery collected using a MBB/Kawasaki BK 117 helicopter flying at 900-1,500 ft AGL.

Additionally for disaster response, debris and damage characterization are often some of the most costly and important tasks. Moy et al. [147] flew a Cessna 206 across sixteen missions for 38.9 flight hours at 2,000 ft AGL to categorize more than twenty thousand pieces of marine debris. Chen et al. [148] used the slightly larger Cessna 210L at 1,000 ft AGL, presumably at a cruise speed of 140 knots, to surveil bridges. Airspeed is presumed based upon Chen et al.'s description of the operation.

\section{Statistical Encounter Models}

For many aviation safety studies, manned aircraft behavior is represented using encounter models, which are statistical models of how aircraft behave during close encounters. They are used to provide a realistic representation of the range of encounter flight dynamics where an aircraft collision avoidance system would be likely to alert. In 2000, Kuchar and Yang reviewed modeling methods [149]. Our review focuses on the models widely used to support aircraft collision avoidance systems. The first models were of aircraft equipped with transponders that are cooperatively sharing information, and only allowed vertical motion. These models built starting in the 1980s by the MITRE Corporation from 12 radar sites supported the development and certification of TCAS [150], [151].

To support the following worldwide TCAS mandates, the International Civil Aviation Organization (ICAO) and Eurocontrol developed more complex models which simulated threedimensional encounters but allowed only a single maneuver in each dimension during an encounter [152]. Specifically, the first statistical European model [153] was developed at the turn of century using months of ground radar surveillance over the United Kingdom and France. The model was dependent upon altitude. Chabert and Arino noted this initial model was insufficient for simulating encounters above $29,000 \mathrm{ft}$ MSL and the model was supplemented with ATC simulation data [154]. Notably for our low altitude review, the lowest the European model considered for 1,000-5,000 ft which reflects the model's emphasis on evaluating larger manned aircraft collision avoidance systems.

The need for three-dimension models with multiple acceleration points was identified in 2006 to support manned and unmanned safety analysis [155]. In response starting in 2008, MIT Lincoln Laboratory (MIT LL) has been developing more advanced encounter models to represent a wider range of encounters [156]. Each MIT LL encounter model is a Bayesian Network, a representation of a multivariate probability distribution as a directed acyclic graph [157] and trained using aircraft operational data derived from radar or other sensing system flight track data. These Bayesian network encounter models were initially used in the evaluation of TCAS II Version 7.1 [158]-[160] and have supported subsequent manned [10], [161]-[164] and unmanned [5], [6], [9], [165]-[167] studies. It is also important to emphasis that while these models are widely used to support TCAS and its variants, they are not the only aircraft simulations utilized [168]-[171]. Across the encounter-based analyses, the five primary types of these models are:

- Uncorrelated Encounter Model of the U.S. National Airspace System: used to evaluate system performance when at least one aircraft is noncooperative or neither aircraft is in contact with ATC [172]; updated and incorporated littoral regions [173] in 2013 [12], [174].

- Correlated Encounter Model of the U.S. National Airspace System: used to evaluate the system performance when both aircraft are cooperative and at least one aircraft is receiving ATC services [175]; updated in 2018 [176].

- Encounter Models for Unconventional Aircraft: used to evaluate system performance when encountering unconventional aircraft, which are unlikely to carry a transponder [177].

- Due Regard Encounter Model: used to evaluate systems for when an UAS flying due regard in oceanic airspace [178].

- Helicopter Air Ambulance Model: used to evaluate system performance when encountering a HAA [5].

To develop the uncorrelated and correlated encounter models, radar data was used from the 84th Radar Evaluation Squadron (RADES) at Hill AFB, Utah. RADES receives radar data from FAA and Department of Defense sites throughout the United States. They maintain continuous real-time feeds from a network of sensors with radar ranges varying from 60$250 \mathrm{~nm}$. Recently these models were updated to include the offshore environment out to the limits of radar coverage [12]. The unconventional aircraft encounter model was developed using weather balloon data and GPS data from volunteered pilot reports [177]; the due regard model with self-reported positions of aircraft flying in oceanic airspace observed by Traffic Flow Management System (TFMS) (formerly Enhanced Traffic Management System) [178]; and the HAA with aircraft 
onboard Flight operational quality assurance (FOQA) data from the Boston metropolitan area. Only the unconventional and HAA models specify aircraft type, such as rotorcraft or paraglider.

Unfortunately, these data sources have limited observations at low altitudes and the resulting models are likely not fully representative of low altitude operations. For example, the uncorrelated model [12], previously used for low altitude encounters, was from 1200-code VFR aircraft tracks of which only $15 \%$ were at or below $1200 \mathrm{ft}$ AGL, and whose lowest initial simulated altitude is $500 \mathrm{ft}$ AGL. Interestingly, the spraying airspeeds in TABLE I align approximately with the median of the airspeed distribution in the uncorrelated encounter model. Conversely, the HAA model was trained with approximately $50 \%$ of FOQA reports at $1200 \mathrm{ft}$ MSL or less. This resulted in a model with a quantization tailored to low altitudes with a cut point below $500 \mathrm{ft}$ MSL. However, as noted in Section II-B, HAA operations are very specialized and the HAA model may not be representative of other low altitude operations. Furthermore the altitude distributions of unconventional airships range from 800-1,400 ft AGL, with the altitude distribution of many unconventional unpowered heavier-than-air airships peaking below 2,000 ft AGL [177]. However, the unconventional model has been sparingly used compared to the other MIT LL models.

A consequence is that low altitude behavior has often been generalized. Carbone et al. proposed an aircraft collision avoidance algorithm with the assumption of a light aircraft operating a constant airspeed of about 88 knots [179]. For non-tower airport simulations, Mahboubi and Kochenderfer, assumed aircraft flight speeds to be uniformly distributed between approximately 83-95 knots [171]. For an exploration of TCAS for general aviation (GA) aircraft, Billinglsey et al. constrained a GA aircraft's vertical rate to range from $-1,000$ to $1,000 \mathrm{ft} / \mathrm{min}$ yet did not make any special changes to account for the slower GA airspeeds [163]. Additional research similar to Edwards at el. [177], which characterized unconventional aircraft, is sorely needed. A newer model [180] focused on the low altitude environment is currently being developed using the OpenSky crowdsourced dataset [181] to address this low altitude modeling capability gap.

\section{Discussion}

Based on the identification of over one hundred operations, we analyze distribution of identified aircraft and compare their performance with existing models and assumptions.

\section{A. Aircraft Type and SWaP}

Foremost, it should not be assumed that aircraft that operate at low altitudes, only exclusively operate at these altitudes. For example, we cited a De Havilland DHC-6 Twin Otter flown below 1,000 ft [101] but Xiao et al. [182] also flew a Twin Otter at $12,500 \mathrm{ft}$ MSL. The specific aircraft identified in the previous sections that operated at low altitudes include:

- AStar AS350

- Air Tractor 301, 402B, 502B, 602

- Beechcraft King Air 90
- Bombardier Dash-8

- Bell 47, 206, 212, Jet Ranger III

- Cessna 152, 172, 180, 185, 206, 207, 208, 210, 401, 402

- Cirrus SR20

- De Havilland DHC-6 Twin Otter

- Diamond DA20, DA40

- Enstrom 408B

- Eurocopter AS365, EC130, H130

- Hiller UH-12

- Let L-410 Turbolet

- Piper PA-18, PA-28, PA-31

- Robinson R44

We characterized these aircrafts and their variants using the FAA manned aircraft characteristics database [183]. Weinert et al. [5] used an earlier version of this database to estimate the sum of wingspans between pairs of aircraft at low altitudes; this metric is important when characterizing airborne collision risk [184]. The physical dimensions of 733 aircraft are plotted in Fig. 3, with the identified aircraft and variants highlighted in red.

Many of these identified aircraft are commonly used for general aviation in addition to the specific commercial use cases explored in this review. Of the aircraft identified, the Bombardier Dash 8-200 used for habitat mapping [102], formally by De Havilland Canada, with a wingspan of $85 \mathrm{ft}$ was the outlier and we exclude it from additional analysis. Also not included are ultralights, a specific type of aircraft often associated with general aviation. Markowski [185] generalized ultralight aircraft as having cruise speeds of approximately 43 knots with stall speeds as slow as 22 knots and vertical rates of $500 \mathrm{ft} / \mathrm{min}$.

Excluding the Dash 8-200, 90\% of identified aircraft had a wingspan less than $53 \mathrm{ft}$ and a length less than $37 \mathrm{ft}$. About two thirds of aircraft were single engine and only 6 aircraft had a weight greater than $10,000 \mathrm{lbs}$. With a few exemptions, these wingspans are less than the fiftieth percentile from Fig. 3, with many smaller than the lowest quartile. These distributions support a previous assertion [5] that the sum of wingspans between a small UAS and manned aircraft below 1,200 ft AGL to be very likely less than $50 \mathrm{ft}$ and unlikely to exceed $100 \mathrm{ft}$.

\section{B. Comparison to Previous Assumptions}

The type of aircraft operating at low altitudes met our expectations. Majority of identified aircraft were single engine rotor craft and fixed-wing single engine. Slight larger aircraft such as the Cessna 206 and Piper Navajo 350, were less common; and larger aircraft than these were rare outliers.

However, the use of these aircraft are more nuanced. Notably 14 CFR 137 agricultural operations discussed in Section II-A are not exclusive to aircraft spraying just above the ground. 14 CFR 137 operations can occur at a few hundred feet. There is also a distinct difference in operational altitudes between agricultural spraying and release operations (Section II-A) and remote sensing for agriculture (Section III-C). These differences illustrates that categorizing operations by general industries, such as agricultural, is insufficient.

These distinctions are evident when comparing to the statistical models discussed in Section IV. For example, the 
FAA aircraft characteristics database
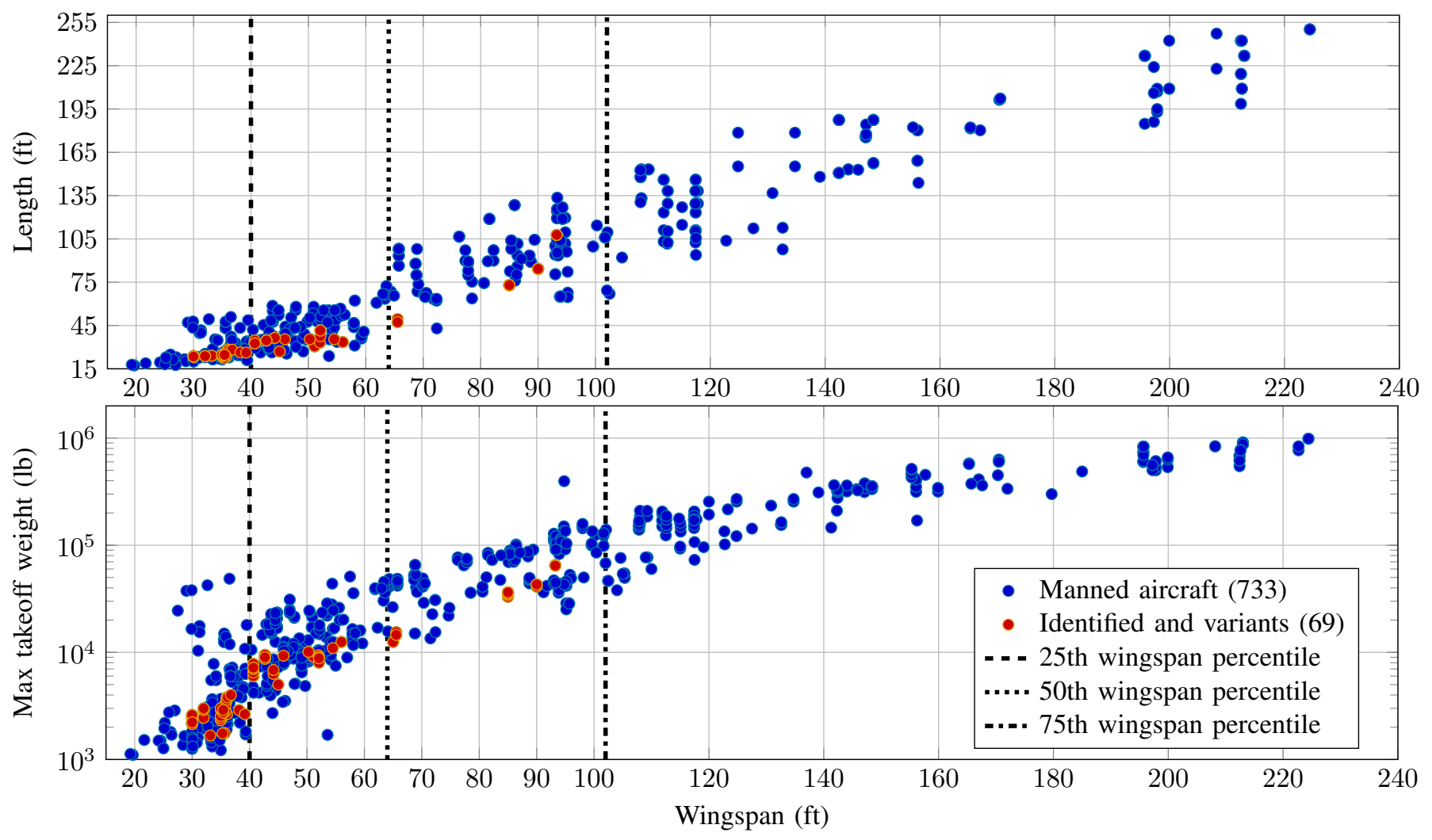

Fig. 3. FAA manned aircraft characteristics database wingspan distribution for 733 manned aircraft. Aircraft identified in the literature and their variants are highlighted in orange. Wingspan quantiles are illustrated for all aircraft.

spraying airspeeds of 97-120 knots reported in TABLE I generally align well with the median airspeed of the statistical uncorrelated encounter model [12]. Whereas many of the airspeeds for animal sciences identified in Section III-A, are less than 60 knots and are not well represented by the uncorrelated encounter model [12] while also violating the manned airspeed assumption used to recommend a sUAS well clear definition [5]. Additionally, the existing statistical models do not capture the expected dynamics of many rotor craft operations.

By reviewing specific operations rather than general trends, differences between reported airspeeds and manufacturer airspeeds were identified. Consider the Air Tractor 602 in Barbosa et al. [31], reported a spraying speed of 105 knots, but the Air Tractor manufacturer reported ${ }^{1}$ a typical working speed of 126 knots and a cruise speed of 158 knots. Similarly, the Enstrom 408B in Jung et al. [89] searched at 49-75 knots, but the Enstrom manufacturer ${ }^{2}$ reported a maximum cruise speed of 109-115 knots. These differences are important for safety assessments. For both these operations, assuming the faster manufacturer's airspeeds would likely result in a greater risk as part of a safety assessment.

\footnotetext{
${ }^{1}$ https://airtractor.com/aircraft/at-602/ (Retrieved 03/04/2018)

${ }^{2}$ http://enstromhelicopter.com/wp-content/uploads/2012/03/enstrom-480bspecifications.pdf (Retrieved 03/04/2018)
}

\section{Data Availability}

Strikingly, some of the best publications for aviation research where published outside of the aviation community, such as Grubb et al. [65], Stoll et al. [78], and Crosman et al. [141]. Expanding this review beyond the aviation community yielded significant information for some use cases, such as for the Animal Sciences discussed in Section III-A. Grubb et al. research focus, in particular, was on golden eagles.

Unfortunately studies like Grubb et al. [65] are one off examples, and for almost all operations reviewed there is a lack of a cohesive record of operations. The quality of flight hour data ranges widely across operations. Flight hour summary statistics are easily available for helicopter offshore operations [71]; conservative estimates from incomplete data are possible for collegiate aviation training programs [72]; estimates are possible a specific news gathering user but not operations [141]; and as noted, insufficient data is available for many operations.

Specifically, Fox [186] in a historical review of helicopter safety noted accurate flight hour exposure data is critical for understanding risk but is difficult to obtain:

A roadblock to the helicopter industry is the lack of accurate flight hour exposure data. If we cannot measure risk, we cannot tell whether our improvement is an actual improvement in safety, or whether it made 
the problem worse or just moved the problem into another area. We must be able to accurately measure the bad outcomes per units of exposure. Exposure data is critical, but difficult to obtain. Availability of flight hours has been a constant problem. FAA General Aviation and Avionics Survey used a sampling technique to estimate flight hours on annual basis. Although this technique produced errors from year to year on an individual model, hours over 5+ year period has improved accuracy, as the annual high/low errors start to cancel each other out. The FAA stopped providing helicopter model flight hours in 1997, so there are no Government flight hour data available at the model level for the years since 1996.

Similarly, when comparing the safety between offshore and onshore helicopter operations, Bye et al. [69] also noted that the key issue was poor data collection methodology, specifically the lack of flight-hour data. Haaland et al. [51] identified a similar challenge with the lack of flight hour and exposure data for helicopter air tours. For helicopters, it appears that policies and regulations that led to higher operating altitudes or a reduction in flight hours, both which can be potentially considered reducing the safety risk exposure, were in response to noise complaints rather than safety driven.

\section{CONCLUSION}

With a renewed emphasizes on the low altitude environment due to the integration of sUAS into the U.S National Airspace System (NAS) and the lack of standardized reporting for many low altitude operations, we conducted an intensive literature review to characterize manned operations at low altitudes. The review covered a wide range of operations and consisted of reviewing publications both inside and outside of the aviation community. This review will support safety assessments or requirements gathering to integrate sUAS at low altitudes.

Future work should focus on characterizing specific trajectories and dynamics of the identified low altitude operations. For example, our review does not validate the assumption that helicopters largely operate similar to general aviation aircraft [187], regardless of a helicopter's unique operating envelope that includes hovering. Instead this review focuses on identifying where and why helicopters operate.

\section{ACKNOWLEDGMENT}

We greatly appreciate the support and assistance provided by Sabrina Saunders-Hodge, Karl Garman, Adam Hendrickson, and William Oehlschlager from the Federal Aviation Administration. We also like to thank fellow MIT Lincoln Laboratory staff Dr. Rodney Cole, Matthew Edwards, and Ngaire Underhill.

\section{REFERENCES}

[1] K. S. Christie, S. L. Gilbert, C. L. Brown, M. Hatfield, and L. Hanson, "Unmanned aircraft systems in wildlife research: Current and future applications of a transformative technology," Frontiers in Ecology and the Environment, vol. 14, no. 5, pp. 241-251, 2016.

[2] D. Appelbaum and R. A. Nehmer, "Using Drones in Internal and External Audits: An Exploratory Framework," Journal of Emerging Technologies in Accounting, vol. 14, no. 1, pp. 99-113, 2017.
[3] D. W. Schuldt and J. A. Kurucar, "Efficient partitioning of space for multiple UAS search in an unobstructed environment," International Journal of Intelligent Robotics and Applications, vol. 2, no. 1, pp. 98109, Mar. 2018.

[4] A. C. Lee, M. Dahan, A. J. Weinert, and S. Amin, "Leveraging sUAS for Infrastructure Network Exploration and Failure Isolation," Journal of Intelligent \& Robotic Systems, Apr. 2018.

[5] A. Weinert, S. Campbell, A. Vela, D. Schuldt, and J. Kurucar, "WellClear Recommendation for Small Unmanned Aircraft Systems Based on Unmitigated Collision Risk," Journal of Air Transportation, vol. 26, no. 3, pp. 113-122, 2018.

[6] S. P. Cook, D. Brooks, R. Cole, D. Hackenberg, and V. Raska, "Defining Well Clear for Unmanned Aircraft Systems," in AIAA Infotech @ Aerospace, ser. AIAA SciTech Forum. American Institute of Aeronautics and Astronautics, Jan. 2015.

[7] J. Clark and A. McFarland, "Initial Collision Avoidance Algorithms for the Beacon-based Collision Avoidance System," The MITRE Corporation, MITRE Technical Report FAA-RD-77-163, Apr. 1977.

[8] J. W. Andrew, "Pilot Evaluation of TCAS in the Long Ranger Helicopter," Massachusetts Institute of Technology, Lincoln Laboratory, Project Report ATC-136, Jun. 1986.

[9] M. J. Kochenderfer and J. P. Chryssanthacopoulos, "Robust airborne collision avoidance through dynamic programming," Lincoln Laboratory, Massachusetts Institute of Technology, Project Report ATC-371, Jan. 2011.

[10] J. E. Holland, M. J. Kochenderfer, and W. A. Olson, "Optimizing the Next Generation Collision Avoidance System for Safe, Suitable, and Acceptable Operational Performance," Air Traffic Control Quarterly, vol. 21, no. 3, pp. 275-297, 2013.

[11] J. Morrel, "Fundamental physics of the aircraft collision problem," Bendix Corporation, Technical Memo 465-1016-39, Jun. 1956.

[12] A. J. Weinert, E. P. Harkleroad, J. D. Griffith, M. W. Edwards, and M. J. Kochenderfer, "Uncorrelated Encounter Model of the National Airspace System Version 2.0," Massachusetts Institute of Technology, Lincoln Laboratory, Lexington, MA, Project Report ATC-404, Aug. 2013.

[13] R. J. Lewis, R. D. Johnson, J. E. Whinnery, and E. M. Forster, "AircraftAssisted Pilot Suicides in the United States, 1993-2002," Archives of Suicide Research, vol. 11, no. 2, pp. 149-161, 2007.

[14] H. Salloum, A. Sedunov, N. Sedunov, A. Sutin, and D. Masters, "Acoustic system for Low Flying Aircraft detection," in 2015 IEEE International Symposium on Technologies for Homeland Security (HST), Apr. 2015, pp. 1-6.

[15] National Security Technologies, "Radiological Survey of Downtown Washington DC for the 2009 Presidential Inauguration," U.S. Department of Energy, AMS 2009 Presidential Inauguration Report DOE/NV/25946-684, Mar. 2009.

[16] A. Weinert and N. Underhill, "Generating Representative Small UAS Trajectories using Open Source Data," in 2018 IEEE/AIAA 37th Digital Avionics Systems Conference (DASC), Sep. 2018, pp. 1-10.

[17] K. P. Cantor and C. F. B. Jr, "Mortality among Aerial Pesticide Applicators and Flight Instructors: A Reprint," Archives of Environmental Health: An International Journal, vol. 46, no. 2, pp. 110-116, 1991.

[18] WilburSmith Associates, "Use and Benefits of Aviation in Iowa (2009 Economic Impact Report," Iowa Department of Transportation, Economic Impact Report, 2009.

[19] Iowa Department of Aviation, "2006 Iowa Ag Aviation Summit," Iowa Department of Transportation, Executive Summary, Mar. 2006, published:.

[20] R. R. A. van Doorn, "Accidents in agricultural aviation in the United States: A 28-year investigation," Aviation Psychology and Applied Human Factors, vol. 4, no. 1, pp. 33-39, 2014.

[21] G. A. R. MD and M. W. H. Berner, "Aerial Application Accidents 1968 to 1966," Archives of Environmental Health: An International Journal, vol. 17 , no. 5, pp. 776-784, Nov. 1968.

[22] C. J. Tucker, D. A. Slayback, J. E. Pinzon, S. O. Los, R. B. Myneni, and M. G. Taylor, "Higher northern latitude normalized difference vegetation index and growing season trends from 1982 to 1999," International Journal of Biometeorology, vol. 45, no. 4, pp. 184-190, Nov. 2001.

[23] R. B. Watson, C. C. Kiker, and H. A. Johnson, "The Role of Airplane Dusting in the Control of Anopheles Breeding Associated with Impounded Waters," Public Health Reports (1896-1970), vol. 53, no. 7 , pp. 251-263, Feb. 1938

[24] C. C. Kiker, C. D. Fairer, P. N. Flanary et al., "Further Observations on Airplane Dusting for Anopheles Larvae Control." Southern Medical Journal, vol. 31, no. 7, pp. 808-813, Jul. 1938. 
[25] F. E. Weick, "Aircraft spraying and dusting," Journal of Agricultural and Food Chemistry, vol. 2, no. 11, pp. 546-549, 1954.

[26] D. J. Forsyth and N. D. Westcott, "Carbofuran residues in grasshoppers and vegetation from aerially sprayed prairie pastures: Potential effects on wildlife," Environmental Toxicology and Chemistry, vol. 13, no. 2, pp. 299-306, Feb. 1994

[27] I. W. Kirk, "Aerial spray drift from different formulations of glyphosate," Transactions of the ASAE, vol. 43, no. 3, pp. 555-559, 2000.

[28] Y. Huang, S. J. Thomson, B. V. Ortiz, K. N. Reddy, W. Ding, R. M. Zablotowicz, and J. R. Bright, "Airborne remote sensing assessment of the damage to cotton caused by spray drift from aerially applied glyphosate through spray deposition measurements," Biosystems Engineering, vol. 107, no. 3, pp. 212 - 220, Nov. 2010

[29] Y. Huang, C. Ouellet-Plamondon, S. J. Thomson, and K. N. Reddy, "Characterizing downwind drift deposition of aerially applied glyphosate using $\mathrm{RbCl}$ as tracer," International Journal of Agricultural and Biological Engineering, vol. 10, no. 3, pp. 31-36, May 2017.

[30] N. Woods, I. P. Craig, G. Dorr, and B. Young, "Spray drift of pesticides arising from aerial application in cotton," Journal of Environmental Quality, vol. 30, no. 3, pp. 697-701, 2001.

[31] R. Barbosa, J. Griffin, and C. Hollier, "Effect of spray rate and method of application in spray deposition," Applied engineering in agriculture, vol. 25 , no. 2 , pp. 181-184, 2009

[32] L. T. Tan and K. H. Tan, "Alternative air vehicles for sterile insect technique aerial release," Journal of Applied Entomology, vol. 137, no. s1, pp. 126-141, Jul. 2011.

[33] W. Enkerlin, Guidance for Packing, Shipping, Holding and Release of Sterile Flies in Area-Wide Fruit Fly Control Programmes. Food \& Agriculture Org., 2007, no. 190.

[34] R. O. Cooper, "Aerial Fish Distribution in a Montana Lake," The Progressive Fish-Culturist, vol. 19, no. 4, pp. 190-191, 1957.

[35] T. Hallows, "Stocking fish from the sky," Wildlife Review, pp. 1-11, 2007.

[36] T. L. Bottin, "Propagating $A^{*}$ searching state graphs in order to find a valid instrument approach configuration," $\mathrm{PhD}$ Thesis, Naval Postgraduate School, Monterey, California, Sep. 2007.

[37] R. K. Anoll, R. B. Newman, and E. D. McConkey, "Rotorcraft Low Altitude IFR Benefit/Cost Analysis: Conclusions and Recommendations," Systems Control Technology for the Federal Aviation Administration, Arlington, VA, Final Report (Draft) DOT/FAA/RD-93/22, Oct. 1993.

[38] G. L. Dillingham, N. Clowers, A. Alley, D. Hooper, B. Leary, H. MacLeod, M. Karpman, S. A. Moessbauer, S. Stenersen, F. VangJohnson, and P. Vines, "AVIATION SAFETY: Improved Data Collection Needed for Effective Oversight of Air Ambulance Industry," United States Government Accountability Office, Report to the Chairman, Subcommittee on Aviation, Committee on Transportation and Infrastructure, House of Representatives GAO-07-353, Feb. 2007.

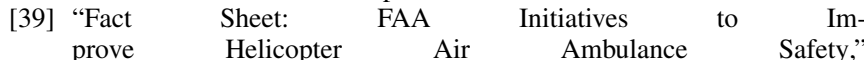
https://www.faa.gov/news/fact_sheets/news_story.cfm?newsId=15794, Feb. 2014, published: fact sheet.

[40] The Association of Air Medical Services, "Fact Sheet and FAQs AAMS," http://aams.org/member-services/fact-sheet-faqs/, Sep. 2016, published: website.

[41] Helicopter Association International, "Improving Safety in Helicopter Emergency Medical Service (HEMS) Operations," http://aams.org/member-services/fact-sheet-faqs/, 2005, published: white paper.

[42] R. Wright Jr, "Air medical service, an industry under scrutiny," Rotor Winter, vol. 2005, pp. 6-8, 2004.

[43] Office of Legislative Audits, "Department of State Police Aviation Command Helicopter Operations," Maryland General Assembly, Baltimore, MD, Performance Audit Report, Aug. 2008.

[44] R. Newman, "Air Ambulance Helicopter Operational Analysis," Systems Control Technology for the Federal Aviation Administration, Arlington, VA, Final Report DOT-FAA-RD-91-7, May 1991.

[45] P. McGeehan, "Rules Tightened for Helicopter Tours," Apr. 2010.

[46] A. Baker and M. L. Wald, "New Rules to Begin for Hudson River Airspace," The New York Times, Nov. 2009.

[47] "FAA Highlights Changes to Hudson River Airspace," http://www.faa.gov/news/updates/?newsId=61526, Sep. 2010.

[48] M. A. V. Chaban, "Deal Restricts Tourist Helicopter Flights Over New York," The New York Times, Dec. 2017.

[49] J. M. Jacquart, "Addressing helicopter noise impacts in Las Vegas, Nevada within the confines of the Airport Noise and Capacity Act," PhD Thesis, University of Nevada Las Vegas, 2002.
[50] S. Canon, "Copter Club Plaza? Aerial tours spark ground-level noise gripes," http://www.kansascity.com/news/local/article135992163.html, Mar. 2017, published: The Kanas City Star

[51] W. L. Haaland, D. F. Shanahan, and S. P. Baker, "Crashes of Sightseeing Helicopter Tours in Hawaii," Aviation, Space, and Environmental Medicine, vol. 80, no. 7, pp. 637-642, Jul. 2009.

[52] M. L. Moss, "Heliports and their importance to New York City," Eastern Region Helicopter Council, Industry Report, Feb. 2012.

[53] Chicago Helicopter Tours, "Chicago Helicopter Tours FAQs," http://www.chicagohelicoptertours.com/about-us/frequently-askedquestions/, Apr. 2016, published: website.

[54] Blue Hawaiian Helicopters, "Circle of Fire plus Waterfalls," http://www.bluehawaiian.com/bigisland/tours/circle_of_fire/, May 2016, published: website.

[55] Sunshine Helicopters, "Big Island Helicopter Tours," http://www.sunshinehelicopters.com/big_island_helicopter_tours.html, May 2016, published: website.

[56] Smoketown Helicopters, "Frequently Asked Questions," https://www.smoketownhelicopters.com/faq.php, Apr. 2016, published: website.

[57] "Las Vegas Night Strip Helicopter Flights," http://lasvegasnightstripflight.com/, May 2016, published: website.

[58] "Sundance Helicopters," http://www.sundancehelicopters.com/lasvegas/, May 2016, published: website.

[59] Maverick "Mours, "Molokai Voyage," http://maverickhelicopter.com/maui/tour-molokai-voyage.aspx, May 2016, published: website.

[60] "Bird's Eye View Helicopters," http://www.newporthelicoptertours.com/, May 2016, published: website.

[61] "HeliNY.com," https://heliny.com/, May 2016, published: website

[62] "Zip Aviation," http://www.zipaviation.com/, May 2016, published: website.

[63] "Pittsburgh Helicopter Rides," http://www.pittsburghhelicoptercharters.com/index.php, May 2016, published: website.

[64] J. Persinos, "Air tour operator Blue Hawaiian is the launch customer for the much touted EC-130B4. By purchasing 10 copies of the B4, company owners Dave and Patti Chevalier have raised the stakes for their entire industry." https://www.bluehawaiian.com/about/articles/hawaiian_punch/, published: website.

[65] T. G. Grubb, D. K. Delaney, and W. W. Bowerman, "Investigating Potential Effects of Heli-Skiing on Golden Eagles in the Wasatch Mountains, Utah," U.S. Department of Agriculture, Forest Service, Final Report to the Wasatch-Cache National Forest, Nov. 2007.

[66] M. I. Goldstein, A. J. Poe, E. Cooper, D. Youkey, B. A. Brown, and T. L. McDonald, "Mountain goat response to helicopter overflights in Alaska," Wildlife Society Bulletin, vol. 33, no. 2, pp. 688-699, 2005.

[67] "AC 90-80B (Cancelled) - Approval of Offshore Standard Approach Procedures (OASP), Airborne Radar Approaches (ARA), and Helicopter En Route Descent Areas (HEDA)," Dec. 2017.

[68] Safety Regulation Group, "The SBAS Offshore Approach Procedure (SOAP)," Civil Aviation Authority, Tech. Rep., May 2010.

[69] R. J. Bye, S. O. Johnsen, and G. Lillehammer, "Addressing Differences in Safety Influencing Factors-A Comparison of Offshore and Onshore Helicopter Operations," Safety, vol. 4, no. 1, 2018.

[70] G. M. Dunnet, "Observations on the effects of low-flying aircraft at seabird colonies on the coast of Aberdeenshire, Scotland," Biological Conservation, vol. 12 , no. 1 , pp. 55 - 63, Jul. 1977.

[71] "2017 Helicopter Safety Advisory Conference (HSAC) Gulf of Mexico Offshore Helicopter Operations and Safety Review," Feb. 2018.

[72] C. J. Christensen and B. H. Dunn, "Fleet Characteristics of Collegiate Aviation Flight Programs," Collegiate Aviation Review, vol. 29, no. 2, pp. 13-20, 2011.

[73] M. Callender, W. Dornan, W. Beckman, P. Craig, and S. Gossett, "Transfer of Skills from Microsoft Flight Simulator X to an Aircraft," 2009 International Symposium on Aviation Psychology, pp. 244-249, Jan. 2009.

[74] C. G. Santel, P. Gerber, S. Mehringskoetter, V. Schochlow, J. Vogt, and U. Klingauf, "How Glider Pilots Misread the FLARM Collision Alerting Display," Aviation Psychology and Applied Human Factors, vol. 4, no. 2, pp. 86-97, Jan. 2014

[75] T. Babb and C. Hiers, "Determination of Takeoff and Landing Distances Using an iPad Performance Application for the Diamond DA40," International Journal of Aviation, Aeronautics, and Aerospace, vol. 5, no. 4 , Aug. 2018. 
[76] S. J. Hook, J. J. Myers, K. J. Thome, M. Fitzgerald, and A. B. Kahle, "The MODIS/ASTER airborne simulator (MASTER) - a new instrument for earth science studies," Remote Sensing of Environment, vol. 76, no. 1, pp. 93-102, Apr. 2001.

[77] J. B. Campbell and R. H. Wynne, Introduction to Remote Sensing, Fifth Edition. Guilford Press, Jun. 2011.

[78] R. J. Stoll, M. W. McClain, J. C. Clem, and T. Plageman, "Accuracy of Helicopter Counts of White-Tailed Deer in Western Ohio Farmland," Wildlife Society Bulletin (1973-2006), vol. 19, no. 3, pp. 309-314, 1991.

[79] M. Gentle, N. Finch, J. Speed, and A. Pople, "A comparison of unmanned aerial vehicles (drones) and manned helicopters for monitoring macropod populations," Wildlife Research, vol. 45, no. 7, pp. 586-595, Nov. 2018

[80] J. C. Hodgson, R. Mott, S. M. Baylis, T. T. Pham, S. Wotherspoon, A. D. Kilpatrick, R. R. Segaran, I. Reid, A. Terauds, and L. P. Koh, "Drones count wildlife more accurately and precisely than humans," Methods in Ecology and Evolution, vol. 9, no. 5, pp. 1160-1167, 2018.

[81] J. Linchant, S. Lhoest, S. Quevauvillers, P. Lejeune, C. Vermeulen, J. S. Ngabinzeke, B. L. Belanganayi, W. Delvingt, and P. Bouché, "UAS imagery reveals new survey opportunities for counting hippos," PLOS ONE, vol. 13, no. 11, p. e0206413, Nov. 2018.

[82] H. Pöysä, J. Kotilainen, V.-M. Väänänen, and M. Kunnasranta, "Estimating production in ducks: A comparison between ground surveys and unmanned aircraft surveys," European Journal of Wildlife Research, vol. 64, no. 6, p. 74, Nov. 2018.

[83] J. Witczuk, S. Pagacz, A. Zmarz, and M. Cypel, "Exploring the feasibility of unmanned aerial vehicles and thermal imaging for ungulate surveys in forests - preliminary results," International Journal of Remote Sensing, vol. 39, no. 15-16, pp. 5504-5521, Aug. 2018.

[84] S. L. Beasom, J. C. Hood, and J. R. Cain, "The effect of strip width on helicopter censusing of deer." Journal of Range Management Archives, vol. 34 , no. 1 , pp. $36-37,1981$

[85] K. S. Christie, W. F. Jensen, and M. S. Boyce, "Pronghorn resource selection and habitat fragmentation in North Dakota," The Journal of Wildlife Management, vol. 81, no. 1, pp. 154-162, 2017.

[86] C. A. DeYoung, "Accuracy of Helicopter Surveys of Deer in South Texas," Wildlife Society Bulletin (1973-2006), vol. 13, no. 2, pp. 146$149,1985$.

[87] S. L. Beasom, F. G. Leon, and D. R. Synatzske, "Accuracy and Precision of Counting White-Tailed Deer with Helicopters at Different Sampling Intensities," Wildlife Society Bulletin (1973-2006), vol. 14, no. 4, pp. 364-368, 1986.

[88] F. Potvin, L. Breton, and L.-P. Rivest, "Aerial surveys for white-tailed deer with the double-count technique in Quebec: Two 5-year plans completed," Wildlife Society Bulletin, vol. 32, no. 4, pp. 1099-1107, 2004.

[89] T. S. Jung, T. E. Chubbs, C. G. Jones, F. R. Phillips, and R. D. Otto, "Winter Habitat Associations of a Low-Density Moose (Alces americanus) Population in Central Labrador," Northeastern Naturalist, vol. 16 , no. 3, pp. 471-481, Sep. 2009.

[90] J. Beringer, L. P. Hansen, and O. Sexton, "Detection Rates of WhiteTailed Deer with a Helicopter over Snow," Wildlife Society Bulletin (1973-2006), vol. 26, no. 1, pp. 24-28, 1998.

[91] R. M. Bartmann, L. H. Carpenter, R. A. Garrott, and D. C. Bowden, "Accuracy of Helicopter Counts of Mule Deer in Pinyon-Juniper Woodland," Wildlife Society Bulletin (1973-2006), vol. 14, no. 4, pp. 356-363, 1986.

[92] H. Jachmann, "Comparison of aerial counts with ground counts for large African herbivores," Journal of Applied Ecology, vol. 39, no. 5, pp. 841-852, 2002.

[93] R. Courtois, A. Gingras, C. Dussault, L. Breton, and J.-P. Ouellet, "An aerial survey technique for the forest-dwelling ecotype of woodland caribou, Rangifer tarandus caribou," The Canadian Field-Naturalist, vol. 117, no. 4, pp. 546-554, 2003.

[94] J. Timmer, M. Butler, W. Ballard, C. Boal, and H. Whitlaw, "Assessment of lesser prairie-chicken lek density relative to landscape characteristics in Texas," Texas Tech University, Tech. Rep. 0000530, Aug. 2012

[95] M. J. Daniels, "Estimating red deer Cervus elaphus populations: An analysis of variation and cost-effectiveness of counting methods," Mammal Review, vol. 36, no. 3, pp. 235-247, 2006.

[96] D. Chabot and C. M. Francis, "Computer-automated bird detection and counts in high-resolution aerial images: A review," Journal of Field Ornithology, vol. 87, no. 4, pp. 343-359, 2016.
[97] G. R. Milton, P. Illsley, and F. M. MacKinnon, "An effective survey technique for large groups of moulting sea ducks," Waterbirds around the world, 2006.

[98] D. Bajzak and J. Piatt, "Computer-Aided Procedure for Counting Waterfowl on Aerial Photographs," Wildlife Society Bulletin, vol. 18, no. 2, pp. 125-129, SUM 1990, wOS:A1990DR12000005

[99] G. Chust, M. Grande, I. Galparsoro, A. Uriarte, and A. Borja, "Capabilities of the bathymetric Hawk Eye LiDAR for coastal habitat mapping: A case study within a Basque estuary," Estuarine, Coastal and Shelf Science, vol. 89, no. 3, pp. 200-213, Oct. 2010.

[100] R. J. Garono, C. A. Simenstad, R. Robinson, and H. Ripley, "Using high spatial resolution hyperspectral imagery to map intertidal habitat structure in Hood Canal, Washington, U.S.A." Canadian Journal of Remote Sensing, vol. 30, no. 1, pp. 54-63, 2004.

[101] H. Su, H. Liu, and W. D. Heyman, "Automated Derivation of Bathymetric Information from Multi-Spectral Satellite Imagery Using a NonLinear Inversion Model," Marine Geodesy, vol. 31, no. 4, pp. 281-298, Dec. 2008.

[102] B. M. Costa, T. A. Battista, and S. J. Pittman, "Comparative evaluation of airborne LiDAR and ship-based multibeam SoNAR bathymetry and intensity for mapping coral reef ecosystems," Remote Sensing of Environment, vol. 113, no. 5, pp. 1082-1100, May 2009.

[103] P. Capolsini, S. Andréfouët, C. Rion, and C. Payri, "A comparison of Landsat ETM+, SPOT HRV, Ikonos, ASTER, and airborne MASTER data for coral reef habitat mapping in South Pacific islands," Canadian Journal of Remote Sensing, vol. 29, no. 2, pp. 187-200, 2003.

[104] K. J. Dalsted, S. Sather-Blair, B. K. Worcester, and R. Klukas, "Application of Remote Sensing to Prairie Dog Management," Journal of Range Management, vol. 34, no. 3, pp. 218-223, 1981.

[105] B. Hörig, F. Kühn, F. Oschütz, and F. Lehmann, "HyMap hyperspectral remote sensing to detect hydrocarbons," International Journal of Remote Sensing, vol. 22, no. 8, pp. 1413-1422, 2001.

[106] P. Li and W. M. Moon, "Land cover classification using MODIS-ASTER airborne simulator (MASTER) data and NDVI: A case study of the Kochang area, Korea," Canadian Journal of Remote Sensing, vol. 30, no. 2, pp. 123-136, 2004

[107] S. Veraverbeke, S. Harris, and S. Hook, "Evaluating spectral indices for burned area discrimination using MODIS/ASTER (MASTER) airborne simulator data," Remote Sensing of Environment, vol. 115, no. 10, pp. 2702-2709, 2011.

[108] J. Tan and K. A. Cherkauer, "Assessing stream temperature variation in the Pacific Northwest using airborne thermal infrared remote sensing," Journal of Environmental Management, vol. 115, pp. 206 - 216, 2013.

[109] M. Zhang, D. English, C. Hu, P. Carlson, F. E. Muller-Karger, G. ToroFarmer, and S. R. Herwitz, "Short-term changes of remote sensing reflectancein a shallow-water environment: Observations from repeated airborne hyperspectral measurements," International Journal of Remote Sensing, vol. 37, no. 7, pp. 1620-1638, 2016.

[110] Q. Zhao and E. A. Wentz, "A MODIS/ASTER Airborne Simulator (MASTER) Imagery for Urban Heat Island Research,” Data, vol. 1, no. 1, Jun. 2016

[111] C. News, "CENIC 2018: Keynote by Ilkay Altintas - Collaborative Data Science in a Highly Networked World," Monterey, CA, Mar. 2018.

[112] T. J. Jackson, D. M. L. Vine, C. T. Swift, T. J. Schmugge, and F. R. Schiebe, "Large area mapping of soil moisture using the ESTAR passive microwave radiometer in Washita'92," Remote Sensing of Environment, vol. 54, no. 1, pp. 27 - 37, 1995.

[113] M. Costa, E. A. Loos, A. Shaw, C. Steckler, and P. Hill, "Hyperspectral imagery for mapping intertidal vegetation at Roberts Bank tidal flats, British Columbia, Canada," Canadian Journal of Remote Sensing, vol. 33, no. 2, pp. 130-141, 2007.

[114] H. E. Greaves, L. A. Vierling, J. U. H. Eitel, N. T. Boelman, T. S. Magney, C. M. Prager, and K. L. Griffin, "High-resolution mapping of aboveground shrub biomass in Arctic tundra using airborne lidar and imagery," Remote Sensing of Environment, vol. 184, pp. 361-373, Oct. 2016.

[115] T. L. Caudle, J. G. Paine, J. R. Andrews, and K. Saylam, "Beach, Dune, and Nearshore Analysis of Southern Texas Gulf Coast Using Chiroptera LIDAR and Imaging System," Journal of Coastal Research, Jan. 2019.

[116] C. Massarelli, R. Matarrese, V. F. Uricchio, M. R. Muolo, M. Laterza, and L. Ernesto, "Detection of asbestos-containing materials in agroecosystem by the use of airborne hyperspectral CASI-1500 sensor including the limited use of two UAVs equipped with RGB cameras," International Journal of Remote Sensing, vol. 38, no. 8-10, pp. 21352149, 2017.

[117] B. G. Marcot, M. T. Jorgenson, and A. R. DeGrange, "Low-altitude photographic transects of the Arctic Network of National Park Units 
and Selawik National Wildlife Refuge, Alaska, July 2013," Data Series, 2014. [Online]. Available: https://dx.doi.org/10.3133/ds846

[118] C. E. Torgersen, R. N. Faux, B. A. McIntosh, N. J. Poage, and D. J. Norton, "Airborne thermal remote sensing for water temperature assessment in rivers and streams," Remote Sensing of Environment, vol. 76, no. 3, pp. $386-398,2001$.

[119] E. Honkavaara, T. Hakala, J. Kirjasniemi, A. Lindfors, J. Mäkynen, K. Nurminen, P. Ruokokoski, H. Saari, and L. Markelin, "New lightweight stereosopic spectrometric airborne imaging technology for highresolution environmental remote sensing case studies in water quality mapping," International Archives of the Photogrammetry, Remote Sensing and Spatial Information Sciences, vol. XL-1/W1, pp. 139-144, May 2013.

[120] L. Mahrt and R. C. Heald, "Nocturnal surface temperature distribution as remotely sensed from low-flying aircraft," Agricultural Meteorology, vol. 28, no. 2, pp. 99 - 107, 1983.

[121] W. Kustas, B. Choudhury, Y. Inoue, P. Pinter, M. Moran, R. Jackson, and R. Reginato, "Ground and aircraft infrared observations over a partially-vegetated area," International Journal of Remote Sensing, vol. 11, no. 3, pp. 409-427, 1990.

[122] J. A. Voogt and C. S. B. Grimmond, "Modeling Surface Sensible Heat Flux Using Surface Radiative Temperatures in a Simple Urban Area," Journal of Applied Meteorology, vol. 39, no. 10, pp. 1679-1699, 2000.

[123] P. J. Pinter, Jr., J. L. Hatfield, J. S. Schepers, E. M. Barnes, M. S. Moran, C. S. Daughtry, and D. R. Upchurch, "Remote Sensing for Crop Management," Photogrammetric Engineering and Remote Sensing, vol. 69, no. 6, pp. 647-664, 2003.

[124] M. Susan Moran, "Irrigation management in Arizona using satellites and airplanes," Irrigation Science, vol. 15, no. 1, pp. 35-44, Sep. 1994.

[125] Y. Huang, K. N. Reddy, S. J. Thomson, and H. Yao, "Assessment of soybean injury from glyphosate using airborne multispectral remote sensing," Pest Management Science, vol. 71, no. 4, pp. 545-552, May 2014.

[126] M. P. Finn, M. D. Lewis, D. D. Bosch, M. Giraldo, K. Yamamoto, D. G. Sullivan, R. Kincaid, R. Luna, G. K. Allam, C. Kvien, and M. S. Williams, "Remote Sensing of Soil Moisture Using Airborne Hyperspectral Data," GIScience \& Remote Sensing, vol. 48, no. 4, pp. 522-540, 2011.

[127] C. Yang, J. H. Everitt, J. M. Bradford, and D. E. Escobar, "Mapping Grain Sorghum Growth and Yield Variations Using Airborne Multispectral Digital Imagery," Transactions of the ASAE, vol. 43, no. 6, pp. 1927-1938, 2000.

[128] C. Yang, J. K. Westbrook, C. P.-C. Suh, D. E. Martin, W. C. Hoffmann, Y. Lan, B. K. Fritz, and J. A. Goolsby, "An Airborne Multispectral Imaging System Based on Two Consumer-Grade Cameras for Agricultural Remote Sensing," Remote Sensing, vol. 6, no. 6, pp. 5257-5278, 2014.

[129] T. Xia, W. P. Kustas, M. C. Anderson, J. G. Alfieri, F. Gao, L. McKee, J. H. Prueger, H. M. E. Geli, C. M. U. Neale, L. Sanchez, M. A. Maria, and Z. Wang, "Mapping evapotranspiration with high-resolution aircraft imagery over vineyards using one- and two-source modeling schemes," Hydrology and Earth System Sciences, vol. 20, no. 4, pp. 1523-1545, 2016.

[130] R. T. Macomber, "Aerial Photography and Seaplane Reconnaissance to Produce the First Total Distribution Inventory of Submersed Aquatic Vegetation in Chesapeake Bay, Maryland," in Remote Sensing the Coastal and Marine Environment, J. B. Zaitzeff, P. Cornillon, and A. D. A, Eds., Rhode Island, 1979.

[131] P. Krishnan, J. Kochendorfer, E. J. Dumas, P. C. Guillevic, C. B. Baker, T. P. Meyers, and B. Martos, "Comparison of in-situ, aircraft, and satellite land surface temperature measurements over a NOAA Climate Reference Network site," Remote Sensing of Environment, vol. 165, pp. 249-264, Aug. 2015.

[132] P. H. Sampson, P. M. Treitz, and G. H. Mohammed, "Remote Sensing of Forest Condition in Tolerant Hardwoods: An Examination of Spatial Scale, Structure and Function," Canadian Journal of Remote Sensing, vol. 27, no. 3, pp. 232-246, 2001.

[133] R. M. Menges, P. R. Nixon, and A. J. Richardson, "Light Reflectance and Remote Sensing of Weeds in Agronomic and Horticultural Crops," Weed Science, vol. 33, no. 4, pp. 569-581, 1985.

[134] F. Liebisch, N. Kirchgessner, D. Schneider, A. Walter, and A. Hund, "Remote, aerial phenotyping of maize traits with a mobile multi-sensor approach," Plant Methods, vol. 11, no. 1, p. 9, Feb. 2015.

[135] R. Näsi, E. Honkavaara, M. Blomqvist, P. Lyytikäinen-Saarenmaa, T. Hakala, N. Viljanen, T. Kantola, and M. Holopainen, "Remote sensing of bark beetle damage in urban forests at individual tree level using a novel hyperspectral camera from UAV and aircraft," Urban Forestry \& Urban Greening, vol. 30, pp. 72-83, Mar. 2018.

[136] R. Calderón, J. A. Navas-Cortés, and P. J. Zarco-Tejada, "Early Detection and Quantification of Verticillium Wilt in Olive Using Hyperspectral and Thermal Imagery over Large Areas," Remote Sensing, vol. 7, no. 5, pp. 5584-5610, 2015.

[137] K. O. Niemann, G. Quinn, R. Stephen, F. Visintini, and D. Parton, "Hyperspectral Remote Sensing of Mountain Pine Beetle with an Emphasis on Previsual Assessment," Canadian Journal of Remote Sensing, vol. 41, no. 3, pp. 191-202, 2015.

[138] L. K. Kliment, K. Rokhsaz, J. Nelson, B. Terning, and E. M. Weinstein, "Usage and Flight Loads Analysis of King Airs in Aerial Firefighting Missions," Journal of Aircraft, vol. 52, no. 3, pp. 910-916, 2015.

[139] K. Rokhsaz and L. K. Kliment, "Derived Gust Velocities Extracted from Flight Data for Various Aircraft," in 57th AIAA/ASCE/AHS/ASC Structures, Structural Dynamics, and Materials Conference. San Diego, California: American Institute of Aeronautics and Astronautics, Jan. 2016.

[140] L. K. Kliment, K. Rokhsaz, J. Nelson, and B. Terning, "Airframe Usage and Operational Loads of ASM/Lead Aircraft in USFS Service," in 2018 AIAA/ASCE/AHS/ASC Structures, Structural Dynamics, and Materials Conference, ser. AIAA SciTech Forum. Kissimmee, Florida: American Institute of Aeronautics and Astronautics, Jan. 2018.

[141] E. T. Crosman, A. A. Jacques, and J. D. Horel, "A novel approach for monitoring vertical profiles of boundary-layer pollutants: Utilizing routine news helicopter flights," Atmospheric Pollution Research, vol. 8 , no. 5 , pp. $828-835,2017$

[142] T. Taylor, "About those helicopters: Q\&A with KTVU's news director," Oct. 2011.

[143] L. Gui, B. Liu, H. C. Wu, Y. Li, and W. Ma, "Helicopter-Based Digital Electronic News Gathering (H-DENG) System: Case Study and System Solution," IEEE Transactions on Broadcasting, vol. 57, no. 1, pp. 121128, Mar. 2011.

[144] M. Lega, C. Ferrara, G. Persechino, and P. Bishop, "Remote sensing in environmental police investigations: Aerial platforms and an innovative application of thermography to detect several illegal activities." Environmental Monitoring And Assessment, vol. 186, no. 12, pp. 8291 - 8301, 2014.

[145] G. P. Alpert, Helicopters in Pursuit Operations, ser. Research in Action, U. S. D. of Justice, Ed. National Institute of Justice, Aug. 1998.

[146] J. Amendt, S. Rodner, C.-P. Schuch, H. Sprenger, L. Weidlich, and F. Reckel, "Helicopter thermal imaging for detecting insect infested cadavers," Science \& Justice, vol. 57, no. 5, pp. 366 - 372, Sep. 2017.

[147] K. Moy, B. Neilson, A. Chung, A. Meadows, M. Castrence, S. Ambagis, and K. Davidson, "Mapping coastal marine debris using aerial imagery and spatial analysis," vol. 132, pp. 52-59. [Online]. Available: http://www.sciencedirect.com/science/article/pii/ S0025326X17310020

[148] S.-E. Chen, C. Rice, C. Boyle, E. Hauser, and B. Philbrick, "Small-format fly-over photography for highway bridge monitoring," in Sensors and Smart Structures Technologies for Civil, Mechanical, and Aerospace Systems 2010, vol. 7647. International Society for Optics and Photonics, p. 76473G. [Online]. Available: https://www. spiedigitallibrary.org/conference-proceedings-of-spie/7647/76473G/ Small-format-fly-over-photography-for-highway-bridge-monitoring/ 10.1117/12.847652.short

[149] J. K. Kuchar and L. C. Yang, "A review of conflict detection and resolution modeling methods," IEEE Transactions on Intelligent Transportation Systems, vol. 1, no. 4, pp. 179-189, Dec. 2000.

[150] M. P. McLaughlin, "Safety study of the Traffic Alert and Collision Avoidance System (TCAS II),” MITRE Corporation, MITRE Technical Report MTR 97W32, Jun. 1997.

[151] J. Lebron, "System Safety Study of Minimum TCAS II," The MITRE Corporation, Final Report MTR-83W241, Dec. 1983.

[152] M. J. Kochendedrfer, L. P. Espindle, J. K. Kuchar, and J. D. Griffith, "A Comprehensive Aircraft Encounter Model of the National Airspace System," Lincoln Laboratory Journal, vol. 17, no. 2, pp. 41-53, 2008.

[153] T. Miquel and K. Thierry, "European Encounter Model: Specifications and probability tables," CENA/Sofréavia and QinetiQ, Technical Report ACASA/WP1/186 version 2.1, Dec. 2001.

[154] S. Chabert and T. Arino, "ACAS PROGRAMME: ACAS Safety Study Safety Benefit of ACAS II Phase 1 and Phase 2 in the New European Airspace Environment," ACAS Programme EHQ, Released Issue ACAS/02-022, May 2002.

[155] A. Zeitlin, A. Lacher, J. Kuchar, and A. Drumm, "Collision Avoidance for Unmanned Aircraft: Proving the Safety Case," The MITRE Corpo- 
ration and Massachusetts Institute of Technology, Lincoln Laboratory, Tech. Rep. MP-060219, Oct. 2006.

[156] M. J. Kochenderfer, M. W. M. Edwards, L. P. Espindle, J. K. Kuchar, and J. D. Griffith, "Airspace Encounter Models for Estimating Collision Risk," Journal of Guidance, Control, and Dynamics, vol. 33, no. 2, pp. 487-499, March-April 2010.

[157] K. P. Murphy, "Dynamic bayesian networks: Representation, inference and learning," PhD Thesis, University of California, Berkeley, 2002.

[158] B. J. Chludzinski, "Evaluation of TCAS II Version 7.1 Using the FAA Fast-Time Encounter Generator Model," Massachusetts Institute of Technology, Lincoln Laboratory, Project Report ATC-346 Volume 1, Apr. 2009.

[159] , "Evaluation of TCAS II Version 7.1 Using the FAA FastTime Encounter Generator Model-Appendix," Massachusetts Institute of Technology, Lincoln Laboratory, Project Report ATC-346 Volume 2, Apr. 2009

[160] L. P. Espindle, J. D. Griffith, and J. K. Kuchar, "Safety Analysis of Upgrading to TCAS Version 7.1 Using the 2008 U.S. Correlated Encounter Model," Project Report ATC-349, Massachusetts Institute of Technology, Lincoln Laboratory, Tech. Rep., 2009.

[161] M. J. Kochenderfer and J. P. Chryssanthacopoulos, "A DecisionTheoretic Approach to Developing Robust Collision Avoidance Logic," in IEEE International Conference on Intelligent Transportation Systems, Madeira Island, Portugal, Sep. 2010, pp. 1837-1842.

[162] J. D. Griffith and W. Olson, "Coordinating general aviation maneuvers with TCAS Resolution Advisories," Massachusetts Institute of Technology, Lincoln Laboratory, Project Report ATC-374, 2011.

[163] T. B. Billingsley, M. J. Kochenderfer, and J. P. Chryssanthacopoulos, "Collision avoidance for general aviation," IEEE Aerospace and Electronic Systems Magazine, vol. 27, no. 7, pp. 4-12, Jul. 2012.

[164] F. Netjasov, A. Vidosavljevic, V. Tosic, M. H. C. Everdij, and H. A. P. Blom, "Development, validation and application of stochastically and dynamically coloured Petri net model of ACAS operations for safety assessment purposes," Transportation Research Part C: Emerging Technologies, vol. 33, pp. 167 - 195, 2013.

[165] J. Griffith, M. Kochenderfer, and J. Kuchar, "Electro-Optical System Analysis for Sense and Avoid," in AIAA Guidance, Navigation and Control Conference and Exhibit. Honolulu, Hawaii: American Institute of Aeronautics and Astronautics, Aug. 2008.

[166] R. E. Weibel, M. W. M. Edwards, and C. S. Fernandes, "Establishing a Risk-Based Separation Standard for Unmanned Aircraft Self Separation," in Ninth USA/Europe Air Traffic Management Research \& Development Seminar. American Institute of Aeronautics and Astronautics, Sep. 2011.

[167] A. Weinert, "A signals processing and big data framework for Monte Carlo aircraft encounters," in 2015 IEEE High Performance Extreme Computing Conference (HPEC), Sep. 2015, pp. 1-6.

[168] Evan Maki, Andrew Weinert, and Mykel Kochenderfer, "Efficiently Estimating Ambient Near Mid-Air Collision Risk for Unmanned Aircraft*," in 10th AIAA Aviation Technology, Integration, and Operations (ATIO) Conference, ser. Aviation Technology, Integration, and Operations (ATIO) Conferences. American Institute of Aeronautics and Astronautics, Sep. 2010.

[169] D. Asmar and M. Kochenderfer, "Optimized Airborne Collision Avoidance in Mixed Equipage Environments," Massachusetts Institute of Technology, Lincoln Laboratory, Lexington, MA, Project Report ATC408, May 2013.

[170] R. E. Tompa, B. Wulfe, M. J. Kochenderfer, and M. P. Owen, "Horizontal Maneuver Coordination for Aircraft Collision-Avoidance Systems," Journal of Aerospace Information Systems, vol. 15, no. 2, pp. 92-106, 2018.

[171] Z. Mahboubi and M. J. Kochenderfer, "Autonomous air traffic control for non-towered airports," in Eleventh USA/Europe Air Traffic Management Research and Development Seminar, Lisbon, Portugal, Jun. 2015, pp. 1-6.

[172] M. J. Kochenderfer, J. K. Kuchar, L. P. Espindle, and J. D. Griffith, "Uncorrelated Encounter Model of the National Airspace System version 1.0," MIT Lincoln Laboratory, Lexington, Massachusetts, Project Report ATC-345, 2008.

[173] M. W. Edwards, "Encounter Models for the Littoral Regions of the National Airspace System," Massachusetts Institute of Technology, Lincoln Laboratory, Tech. Rep. CASSATT-2, Sep. 2010.

[174] A. J. Weinert, E. Harkleroad, J. Griffith, M. W. Edwards, and C. C. Chen, "Extended Airspace Encounter Models for Unmanned Aircraft Sense and Avoid Safety Evaluation,” in AIAA Infotech@Aerospace (I@A) Conference. Boston, MA: American Institute of Aeronautics and Astronautics, Aug. 2013.
[175] M. J. Kochenderfer, L. P. Espindle, J. K. Kuchar, and J. D. Griffith, "Correlated Encounter Model for Cooperative Aircraft in the National Airspace System," Massachusetts Institute of Technology, Lincoln Laboratory, Project Report ATC-344, 2008.

[176] N. Underhill, E. Harkleroad, R. Guendel, D. Maki, and M. Edwards, "Correlated Encounter Model for Cooperative Aircraft in the National Airspace System; Version 2.0," Massachusetts Institute Technology Lincoln Laboratory Lexington United States, Tech. Rep., May 2018.

[177] M. W. Edwards, M. J. Kochendedrfer, J. K. Kuchar, and L. P. Espindle, "Encounter Models for Unconventional Aircraft, Version 1.0," Massachusetts Institute of Technology, Lincoln Laboratory, Project Report ATC-348, 2009.

[178] J. D. Griffith, M. W. Edwards, R. M. Miraflor, and A. J. Weinert, "Due Regard Encounter Model Version 1.0," Massachusetts Institute of Technology, Lincoln Laboratory, Lexington, MA, Project Report ATC-397, Aug. 2013.

[179] C. Carbone, U. Ciniglio, F. Corraro, and S. Luongo, "A Novel 3D Geometric Algorithm for Aircraft Autonomous Collision Avoidance," in Proceedings of the 45th IEEE Conference on Decision and Control, Dec. 2006, pp. 1580-1585.

[180] A. Weinert, N. Underhill, and A. Wicks, "Developing a Low Altitude Manned Encounter Model Using ADS-B Observations," in 2019 IEEE Aerospace Conference, Big Sky, MT, Mar. 2019.

[181] M. Schäfer, M. Strohmeier, V. Lenders, I. Martinovic, and M. Wilhelm, "Bringing up OpenSky: A large-scale ADS-B sensor network for research," in IPSN-14 Proceedings of the 13th International Symposium on Information Processing in Sensor Networks, Apr. 2014, pp. 83-94.

[182] Q. Xiao, S. L. Ustin, and E. G. McPherson, "Using AVIRIS data and multiple-masking techniques to map urban forest tree species," International Journal of Remote Sensing, vol. 25, no. 24, pp. 56375654, 2004.

[183] “Aircraft Characteristics Database," Oct. 2018.

[184] M. Kochenderfer, D. Griffith, and J. Olszta, "On Estimating Mid-Air Collision Risk," in 10th AIAA Aviation Technology, Integration, and Operations (ATIO) Conference, ser. Aviation Technology, Integration, and Operations (ATIO) Conferences. Fort Worth, TX: American Institute of Aeronautics and Astronautics, Sep. 2010.

[185] M. A. Markowski, "Ultralight Airplanes," Scientific American, vol. 247, no. 1, pp. 62-69, 1982.

[186] R. G. Fox, "The history of helicopter safety," in International Helicopter Safety Symposium, Sep. 2005, pp. 26-29.

[187] F. Taylor and R. Adams, "Helicopter User Survey: Traffic Alert Collision Avoidance System (TCAS)," Systems Control Technology for the Federal Aviation Administration, Arlington, VA, Final Report DOT-FAA-PM-85-6, Apr. 1985. 